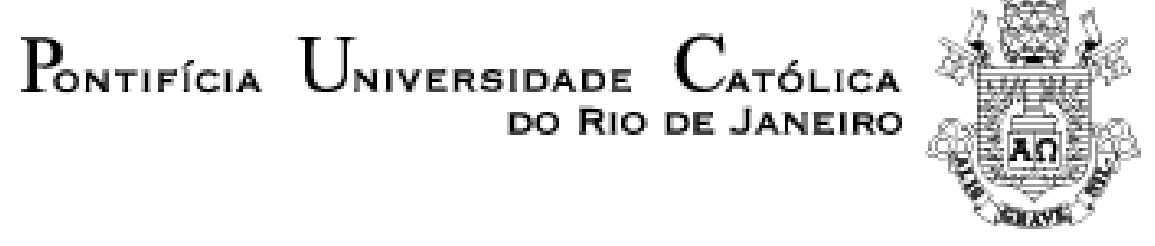

Márcia Correa e Castro

\title{
Enunciar Democracia e Realizar o Mercado \\ Políticas de Tecnologia na Educação até o Proinfo Integrado \\ (1973-2007)
}

\begin{abstract}
Dissertação de Mestrado
Dissertação apresentada como requisito parcial para obtenção do título de Mestre pelo Programa de PósGraduação em Educação do Departamento de Educação da PUC-Rio.
\end{abstract}

Orientador: José Mauricio Paiva Andion Arruti

Rio de Janeiro

Abril de 2011 


\title{
Pontifícia Universidade Católica DO RIO DE JANEIRO
}

\author{
Márcia Correa e Castro
}

\section{Enunciar Democracia e Realizar o Mercado \\ Políticas de Tecnologia na Educação até o Proinfo Integrado}

(1973-2007)

Dissertação apresentada como requisito parcial para obtenção do título de Mestre pelo Programa de PósGraduação em Educação do Departamento de Educação da PUC-Rio. Aprovada pela Comissão Examinadora abaixo assinada.

\author{
Prof. José Mauricio Paiva Andion Arruti \\ Orientador \\ Departamento de Educação - PUC-Rio
}

Profa. Alicia Maria Catalano de Bonamino Departamento de Educação - PUC-Rio

Profa. Maria Helena Silveira Bonilla Universidade Federal da Bahia

Profa. Denise Berruezo Portinari Coordenadora Setorial do Centro de Teologia e Ciências Humanas

Rio de Janeiro, 15 de abril de 2011 
Todos os direitos reservados. É proibida a reprodução total ou parcial do trabalho sem autorização da universidade, da autora e do orientador.

\section{Márcia Correa e Castro}

Graduou-se em comunicação social, habilitação jornalismo, (Universidade Federal Fluminense) em 1993. Fundou em 1992 a Bem TV - Educação e Comunicação, organização não governamental dedicada a desenvolver ações na área de Comunicação e Educação. Foi professora substituta nas áreas de jornalismo comunitário e telejornalismo no Instituto de Artes e Comunicação Social da Universidade Federal Fluminense. Militante do movimento pela Democratização da Comunicação, foi delegada da I Conferência Nacional de Comunicação.

Ficha Catalográfica

Castro, Márcia Correa e

Enunciar democracia e realizar o mercado : políticas de tecnologia na educação até o Proinfo integrado (1973-2007) / Márcia Correa e Castro ; orientador: José Mauricio Paiva Andion Arruti. 2011.

146 f. ; $30 \mathrm{~cm}$

Dissertação (mestrado)- Pontifícia Universidade Católica do Rio de Janeiro, Departamento de Educação, 2011.

Inclui bibliografia

1. Educação - Teses. 2. Tecnologia. 3. Inclusão digital. 4. Proinfo. I. Arruti, José Mauricio Paiva Andion. II. Pontifícia Universidade Católica do Rio de Janeiro. Departamento de Educação. III. Título. 
A todos, e a cada um dos estudantes de escolas públicas brasileiras 


\section{Agradecimentos}

Em primeiríssimo lugar agradeço a Isabela e Francisco, estrelinhas da minha vida, que não apenas souberam compreender minhas ausências, como torceram por mim, compartilhando comigo a alegria de cada etapa vencida.

A Paulo, meu amor, pela paciência, pelo incentivo e pelos primeiros comentários que foram de enorme ajuda.

A Olívia, Daniela, Ana Paula, Regina, Aline, Ana Lúcia, Danielle, Thaís, Letícia, Ivone e Maycon, meus companheiros de Bem TV, por compartilharem comigo o sonho de uma comunicação a serviço de uma educação melhor.

Ao meu orientador, José Maurício Arruti, pela parceria, pela precisão cirúrgica das críticas e pela generosidade dos elogios, fundamentais nos momentos de desânimo.

A meus professores da pós-graduação em educação da PUC-Rio, em especial Alicia Bonamino, Isabel Lélis, Maria Inês Marcondes e Ana Waleska Mendonça e a meus colegas da turma de mestrado 2009, e do Laboratório de Antropologia dos Processos Formativos (LAPF) pelas risadas, pelos debates e pela inestimável sensação de não estar só.

A minha mãe querida, a quem devo o gosto pelos livros e pelo estudo. E ao meu pai, que me apoiou sempre, ainda que na maioria das vezes não concordasse com o que eu estava fazendo.

A meu chefe, Arlindo, pelas licenças e perdões, sem os quais não teria sido possível chegar aqui.

A Gustavo, Renata e Ana Cristina, amigos de primeira hora, pela leitura e discussão dos textos comigo.

A Luisa e Xico, por toda ajuda. 


\section{Resumo}

Correa e Castro, Márcia; Arruti, José Mauricio Paiva Andion (orientador). Enunciar Democracia e Realizar o Mercado: Políticas de Tecnologia na Educação até o Proinfo Integrado (1973-2007). Rio de Janeiro, 2011. 146p. Dissertação de Mestrado - Departamento de Pós-graduação em Educação, Universidade Católica do Rio de Janeiro.

Orientada pela proposta metodológica da Abordagem do Ciclo de Políticas de Stephen Ball e Richardo Bowes (1992) a presente pesquisa busca analisar os contextos de influência e de produção do texto da atual política nacional de tecnologia na educação: o PROINFO (Programa Nacional de Tecnologia Educacional), abordando ainda leituras feitas da política pela Secretaria Estadual de Educação do Rio de Janeiro, leituras estas que orientarão o contexto da prática local da política. Para dar conta de seus objetivos o texto apresenta: (1) o histórico das políticas brasileiras de informática e a tensão entre a busca pela autonomia tecnológica do país e as pressões do mercado externo; (2) o paralelismo entre as políticas gerais de educação e as políticas de tecnologia na escola até a década de noventa, com a posterior convergência entre essas políticas para atender ao mercado; (3) a materialização discursiva da convergência entre educação e tecnologia educacional e as contradições de um texto que enuncia a democracia mas realiza o mercado.

\section{Palavras-chave}

Tecnologia, Inclusão Digital, Proinfo. 


\section{Abstract}

Correa e Castro, Márcia; Arruti, José Mauricio Paiva Andion (Advisor). Stating Democracy and Carry out the Market Technology Policies in Brazilian Education (1973-2007). Rio de Janeiro, 2011, 146p. MSc Dissertation - Departamento de Pósgraduação em Educação, Universidade Católica do Rio de Janeiro.

Based in the Policy Cycle Approach formulated by Stephen Ball and Richard Bowe (1992) this research aims at analyzing the influence an text production contexts of the current Brazilian policy on technology in education: the PROINFO (National Program of Technology in Education). The text also discuss readings of the policy made by the Local government in Rio de Janeiro, witch helps to delineate the policy's context of practice in this state. To meet its objectives, the text presents: (1) the historical survey of the Brazilian ICT policies and the search for technological autonomy facing the pressures of international market; (2)The parallelism between the general policies of education until the nineties; and further convergence between the two policies to satisfy the market; (3) the contradictions expressed in the text of current policy of educational technology, witch states democracy, but realizes the market.

\section{Palavras-chave}

Information society, Technologies, Digital Divide. 


\section{Sumário}

$\begin{array}{ll}\text { Introdução } & 10\end{array}$

1. Contexto Geral 16

1.1. Histórico das Políticas de Informática no Brasil 16

1.2. Influências do Contexto Mundial 28

1.3. Determinismo Tecnológico e Inclusão Digital 34

2. Construindo a Política de Tecnologia Educacional 40

2.1. As Origens e Foco na Escola 45

2.2. Os Primeiros Seminários $\quad 51$

2.3. O Projeto Educom e seus Centros de Pesquisa 54

2.4. Do Proninfe ao Proinfo 63

2.5. Apocalípticos e Integrados. 70

3. Proinfo: Leituras e Releituras. $\quad 80$

3.1.Objetivos Iniciais do Proinfo. $\quad 84$

3.2.Implementação do Programa e Espaços de Participação. 92

3.3.Formação de Professores. 99

3.4. O Proinfo Integrado ao PDE. 106

3.5. O Proinfo no estado do Rio de Janeiro. 121

$\begin{array}{ll}\text { Conclusões } & 133\end{array}$

Referências Bibliográficas $\quad 140$

$\begin{array}{ll}\text { Entrevistas realizadas } & 146\end{array}$ 


\section{Lista de Figuras}

Figura 1 - Cartaz de Promoção do Proinfo 117

Figura 2 - Distribuição dos Distritos de Tecnologia 123

Educacional no estado do Rio de Janeiro

\section{Lista de Quadros}

Quadro 1 - Análise Comparativa das Atividades

Desenvolvidas nos Centros Piloto do Projeto Educom

Quadro 2 - Educação, Informática e Tecnologia

Educacional: Linha do Tempo 